\title{
Espaços ambíguos e a inovação neoliberal contemporânea: 0 caso do Merkén
}

\author{
Alberto Arce \\ Wageningen Universty - Wageningen - Holanda \\ ORCID: https://orcid.org/0000-0002-3856-6363 \\ Flávia Charão-Marques \\ Universidade Federal do Rio Grande do Sul - Porto Alegre - Brasil \\ ORCID: https://orcid.org/0000-0002-1818-9281
}

\begin{abstract}
Resumo
Considerando a exploração dos efeitos materiais de exercícios do poder relacionados à inovação agroalimentar, abordamos a emergência de espaços de ambiguidade sócio material, surgidos da exploração do potencial econômico da agregação de valor a alimentos territoriais. A ilustração empírica vem do caso do Merkén, que é uma combinação de pimentas defumadas e moídas, cuja origem é atribuída ao povo Mapuche, no Chile. 0 reconhecimento das potencialidades do alto valor gastronómico deste condimento o transforma em uma inovação comercial, fazendo surgir tensões entre as formas de produção industrial, semi-industrial e a artesanal. A última, baseada em receitas singulares desenvolvidas por famílias camponesas, provém da relação biocultural entre os atores sociais e o ají-merkén, destacando-se o conhecimento dos ecotipos de pimenta, seu cultivo e do detalhado processo de defumação, além de relações consolidadas em mercados regionais. Identifica-se que, inovar para além do 'comercial', tem a ver com desafio de superar normas padronizadas, que tendem a provocar perda da integridade que identifica o produto com seu território. $O$ artigo, então, mostra que a materialidade envolvida na inovação tem a capacidade de transformar relações de poder e a autoridade que constituem produtos territoriais; e que os espaços de inovação têm natureza ambígua, oscilando entre as vantagens que o mercado oferece e uma multiplicidade de reconfigurações da materialidade e da organização social situada.
\end{abstract}

Palavras-chave: Inovação. Ator Social. Materialidade. Pimenta. Chile.

\section{Ambiguous spaces and the contemporary neoliberal innovation: the case of Merkén}

\section{Abstract}

To explore the material effects of power in processes of agri-food innovation. We focus on the emergence of ambiguous socio-material spaces for innovation. These spaces appeared from a commercial innovation to gather the potential added value embodied in territorial heritage food-products. The case study of Mapuches' Merkén is situated in the community of Santa Juana (Bío-Bío region, Chile). The condiment is a result of the combination of three different types of local chilli-peppers, and of a sophisticated and experiential knowledge on the use of smoke to dehydrate the fruits, as part of heritage properties of a condiment attributed to Mapuches' culinary culture. The recognition of the potential high gastronomic 
value of these chilli-peppers and its handicraft elaboration, it made this commercial innovation interesting to study, as an innovation contributing to the territorial development. However, the scramble that followed for the market control of the heritage added valued, generated deep contradictions, between industrial, semi-industrial and the artisan condiment elaboration. Santa Juana producers' unique recipes are result of generations of peasant families cultivating biocultural relationship between producers and the chilli-merkén. The biocultural study highlights the socio-material chilli-peppers, unique ecotypes existence, the cultivation styles, and producers' detail knowledge of smoking processes to elaborate the Merkén powder. The paper identified producers' long existence regional markets relationships, and recognized that commercial innovation in this case, it has to do with the challenge of overcoming standardized rules and procedures that market produces generally demand. The maintenance of diversity among Merkén producers is paramount. The existence of socio-material differences is an important factor in keeping the integrity identifying a product with its territory. The paper shows that is the socio-materiality involved in processes of innovation where resides the ability to transform or not relations of power and authority, reconstituting territorial products with added value. Finally, we suggest that innovation spaces in the contemporary period has an ambiguous nature. This is characterised by oscillating movements between advantages offered by the market and the multiple reconfigurations assumed by the materiality of power, and the situated producers social organization.

Keywords: Innovation. Social Actor. Materiality. Chilli Pepper. Chile

\section{Espacios ambiguos y la innovación neoliberal contemporánea: el caso de Merkén}

\section{Resumen}

Considerando la exploración de los efectos materiales de los ejercicios de poder relacionados a la innovación agroalimentaria, enfocamos la emergencia de espacios de ambigüedad sociomaterial que surgen de la explotación del potencial económico del valor agregado a los alimentos territoriales. La ilustración empírica proviene del caso de Merkén, que es una combinación de pimientas ahumadas y molidas, cuyo origen se atribuye al pueblo Mapuche, en Chile. El reconocimiento del potencial del alto valor gastronómico de este ají lo convierte en una innovación comercial, provocando tensiones entre la producción industrial, semiindustrial y artesanal. La última, basada en recetas únicas desarrolladas por familias campesinas, proviene de la relación biocultural entre los actores sociales y el ají-merkén, destacando el conocimiento de los ecotipos de pimientas, su cultivo y el proceso detallado del ahumado, además de relaciones consolidadas en mercados regionales. Se identifica que innovar, más allá de lo 'comercial', tiene que ver con el desafío de superar normas estandarizadas, que llevan a la pérdida de integridad que identifica el producto con su territorio. Luego, el artículo muestra que la materialidad involucrada en la innovación tiene la capacidad de transformar las relaciones de poder y la autoridad que constituyen productos territoriales; y que los espacios de innovación son de naturaleza ambigua, oscilando entre las ventajas que ofrece el mercado y una multiplicidad de reconfiguraciones de la materialidad y la organización social situada.

Palabras clave: Innovación. Actor Social. Materialidad. Ají. Chile

\section{Introdução}

A sociologia do conhecimento tem uma longa trajetória nas ciências sociais, mas, é somente no final dos anos 1980 que os componentes sociais do conhecimento começam a ser resgatados das margens da análise sócio antropológica para transformar-se em um elemento central no campo do desenvolvimento rural 
(HOBART, 1993; LONG e LONG, 1992; ARCE,1993; POTTIER, 1993; ARCE e LONG, 1994; OLIVIER DE SARDAN, 1995)

A criação e a transformação do conhecimento, no mundo global contemporâneo, vem adotando uma posição mais construcionista, vis-à-vis uma orientação mais tradicional denominada construtivista. O construtivismo se desenvolve tendo como mais relevante o componente cognitivo, entregando menor relevância à materialidade e ao social. Por outro lado, o construcionismo social é um processo crítico que se baseia em dar importância ao mundo material, o que recentemente passa a ser caracterizado como a perspectiva do novo materialismo (COOLE e FROST, 2010).

Esta orientação, principalmente dirigida a explorar os efeitos materiais dos exercícios do poder, está fortemente enfocada em explorar o que constitui a produção do sócio material e seus afetos nas práticas dos atores, ao fazer, refazer e renovar os mundos existentes. Esta perspectiva tenta ir além do entendimento das estruturas dominantes e hegemônicas, mas também, do consumo das representações que ordenam e tratam de dar estabilidade aos mundos modernos. Aqui, a crítica à obsessão neoliberal, de que a solução para o problema da instabilidade social está no acesso a novos mercados, adquire importância conceitual e prática.

Esta realidade demanda o reconhecimento da existência empírica e situada do mundo neoliberal, de maneira que nem tudo pode ser reduzido à visão de que o mercado é, finalmente, a unidade global que reorienta as direções políticas e sociotécnicas nos diversos contextos da produção de objetos que incorporam diferentes valores. Sob estas circunstâncias, o estudo dos processos de territorialização e desterritorialização das práticas dos atores em seus mundos materiais e em suas experiências de vida, nos permitem indagar: como podemos descrever, entender e analisar a importância dos processos de inovação? Nesta mesma direção, outras questões podem ser levantadas: a importância sócio material de 'produtos inovadores' estaria se deslocando dos seus atributos intrínsecos para a cadeia de comercialização, distribuição e consumo? Isto estaria indicando que o componente sociotécnico nos processos de inovação começa a ter menos protagonismo? Neste ponto, talvez seja pertinente sugerir uma nova ontologia da inovação, como provocação para repensar criticamente a ideia de mudança social dentro do mundo neoliberal contemporâneo.

Nossa proposta pressupõe que o potencial econômico da agregação de valor a produtos territoriais - baseada em atributos gastronômicos de especificidade e qualidade vinculados a sua origem tradicional ${ }^{1}$-, gera um espaço de ambiguidade e de contradições sócio materiais, que estamos entendendo como 'inovação neoliberal'. Neste espaço, se expressam o cultural, o imaginário, o intangível, mostrando uma diversidade de situações e realidades de existência que se

\footnotetext{
1 Entre 1972 y 2003, a UNESCO implementa a Convenção do Patrimônio Mundial Cultural e Natural. Isto torna visível bens culturais como dispositivos da identidade territorial dos cidadãos nos estados nacionais. A partir dos anos 1980, os bens culturais o patrimônio imaterial intangível passa a ser visto como potencial para o desenvolvimento territorial, por exemplo, pelo reconhecimento do 'patrimônio vivo dos indivíduos'. Em 1982, a Declaração do México sobre as Políticas Culturais estabelece as bases para o resgate e a proteção dos bens imateriais. E, desde os anos 1990, desenvolvimento territorial passa a ser entendido como impossível sem 'os atores e a cultura'. Neste marco é que a cultura culinária se transforma na 'materialidade do comer', dando margem para que os alimentos e as cozinhas regionais, ao redor do globo, se tornem visíveis (INTA, 2018).
} 
corporificam na modernidade singularizada do consumo global de objetos específicos de culinárias territoriais.

Esta temática provoca uma variedade de estudos, na América Latina, acerca do potencial culinário/gastronômico, da transformação dos territórios, do surgimento de valores ligados ao patrimônio agroalimentar e acerca da ressignificação dos alimentos e seu componente político (MENASCHE, 2015, ÁVILA et al., 2015, MONTECINOS, 2017). A circulação global destes produtos - alimentos depende de vários fatores sócio materiais como, suas características próprias (i.e, sabor, textura, aparência, propriedades nutricionais e ecológicas), o entorno institucional, os costumes associados, as práticas e procedimentos. Também, depende das expectativas dos produtores, consumidores $e$ as partes comercialmente interessadas nos produtos típicos (ACAMPORA e FONTE, 2007), ou no alcance de uma distinção, por exemplo, por meio da valorização da indicação geográfica ou da denominação de origem de produtos agroalimentares (ver, WILKINSON et al., 2016; PINTO e SIMÕES, 2016; BONANNO et al., 2019).

A tendência da valorização do patrimônio agroalimentar, no Chile, motivou o desenvolvimento de um programa de inovações, tendo como foco a agregação de valor aos alimentos que se consideram 'patrimoniais' (ver CORTÉS e BOZA, 2017), sob o argumento de que podem promover a conservação (dos recursos genéticos, do conhecimento local e das tradições) e o desenvolvimento de territórios, através da comercialização de produtos singulares para a gastronomia global. Trataremos de ilustrar a discussão com o caso da produção de Merkén - condimento a base de pimenta cultivada e processada na localidade chilena de Santa Juana. Especificamente, a diferenciação da qualidade patrimonial do Merkén se estabeleceu como uma oportunidade para que os produtores agregassem valor e encontrassem novos mercados, respondendo às demandas de consumidores, que monetariamente valorizam com seu consumo os atributos deste condimento.

Deve-se notar que a culinária global das pimentas está diretamente relacionada às aptidões varietais das pimentas, desde o cultivo (solo, regime de chuvas, técnicas de manejo, etc.) até a maneira como elas são combinadas em receitas regionais para dar sabor aos alimentos. Isso faz com que a pimenta seja consumida de muitas maneiras e, em muitas partes do mundo, existem diferentes formas de consumo e, portanto, na linguagem neoliberal, muitos mercados. A circulação gastronômica de pimentas vermelhas e verdes em Portugal e Espanha; a calabresa na Itália; molhos de todo tipo, pimenta verde, seca e moída no México; mesclas de pimenta e outras especiarias, pimenta em spray ou líquida são populares na Hungria; no Brasil, por exemplo, há a pouco conhecida 'pimenta de macaco', que se encontra no Território Kalunga - zona do Cerrado de Goiás. É nessa diversidade global do consumo da pimenta, onde está o 'único' - do presente e do passado - da produção artesanal do Merkén da Araucanía chilena. Isso faz parte de uma realidade 'sensorial', que sugere que os mercados não são criações conceituais, mas uma manifestação da interação sócio material dos atores e das materialidades de seus mundos, que se assume como afeto - tangível-intangível - relacionado ao patrimônio alimentar, como uma propriedade do valor gastronômico neoliberal.

No caso de Santa Juana, houve um processo de individualização e coordenação que levou os produtores a existir em uma região que sofreu mudanças dramáticas na demanda por produtos hortícolas - tradição de muitas famílias -, sendo este um dos fatores condicionantes aos agricultores se reposicionar nos mercados 
do Merkém, operando transformações no processo produtivo local. Para explorar essas 'inovações neoliberais' foi adotada uma perspectiva metodológica etnográfica para descrever e analisar os processos sócio materiais territoriais, tais como a capacidade de adaptação e mudanças do conhecimento local relacionados à elaboração artesanal do condimento. ${ }^{2}$

Cabe alertar que, neste artigo, não discutiremos a origem epistemológica da inovação ou os processos que a promovem, tampouco, como replicá-la em termos gerais. O foco será problematizar uma experiência de inovação que surge do reconhecimento do fenômeno da gastronomia a nível mundial, esta tendência global que aborda a inovação através da valorização, principalmente comercial, do patrimônio agroalimentar, dinâmica que faz interacionar o conhecimento tradicional dos atores territoriais com as potencialidades econômicas. O estudo sócio material das pimentas e do Merkén nos levou, muito mais, a explorar a problemática da materialidade do poder com relação aos espaços da inovação contemporânea.

\section{Notas sobre a inovação sob o neoliberalismo}

O mundo neoliberal transformou a socialidade da economia. Ele desloca o foco que dava visibilidade aos produtores e suas atividades tangíveis de produção, para resituá-lo nos consumidores com suas demandas intangíveis e nos objetos que circulam na economia contemporânea. Neste sentido, este mundo neoliberal acaba por atribuir grande importância às condições e vias de distribuição para comercializar os produtos e os bens e serviços de uma sociedade. O neoliberalismo reforça tal dinâmica ao sugerir que, no mundo contemporâneo, a comercialização é uma ação que vai além de 'vender' produtos. Em outras palavras, o desafio do neoliberalismo é construir consumidores que demandem e sejam leais a um produto. É assim que o imperativo é construir esferas de consumo - mercados específicos valorizados pelos consumidores - e promover a inovação, cuja ponto central é agregar valor a um produto (também aos bens e serviços). De certa forma, é justamente aí que as inovações cumprem funções das mais importantes no neoliberalismo contemporâneo.

A inovação neoliberal pode ser entendida como parte de networks (redes) de organizações, empresas e indivíduos, cujo foco é trazer novos produtos, processos e valores, além de novas formas de organização ao que se entende como a atividade econômica do consumo. A esfera do consumo é uma realidade que combina riscos e possibilidades do mundo global, mas também as ambiguidades e contradições das políticas nacionais e a operacionalidade das instituições nacionais e internacionais.

Nesse sentido, a materialidade do conhecimento - a maneira pela qual os atores acessam a informação, transformando o conhecimento em relevante, para incorporá-lo como um valor agregado aos produtos, bens e serviços - é o que hoje se apresenta como inovação neoliberal. Aqui, ao começar a problematizar o 'valor agregado' aos objetos que circulam no mercado, sugerimos que esta é uma ação que

\footnotetext{
2 Este artigo se baseia, em parte, na pesquisa de campo que foi executada, entre os anos de 2017 e 2018, no âmbito do projeto "Merkén de Santa Juana: valorización de Recetas Ancestrales y Rescate de Ajíes Locales", com coordenação da Faculdade de Agronomia da Universidade do Chile, e sob os auspícios do Fondo de Innovación Agraria - FIA - ligado ao Ministério da Agricultura de Chile (Proyecto FIA: PYT-2016-0362) Registra-se que as opiniões e conclusões que se encontram neste artigo são de responsabilidade exclusiva dos autores.
} 
se estende para além da 'geração de conhecimento', provocando contradições e ambiguidades.

Na inovação, a informação científica e a informática, em geral, tem se mostrado como componentes importantes das realidades socioambientais, políticas e econômicas contemporâneas. Elas se transformam muito rapidamente, fazendo aumentar o desafio de como manter uma relevância produtiva e competitiva na esfera do consumo. Neste 'cenário', atores comunitários, privados, estatais e corporativos precisam incorporar pesquisa científica e tecnologia de ponta para inovar. Por outro lado, a adaptação às mudanças nas relações sociais entre atores, instituições, meio ambiente e interações entre os espaços rurais e urbanos são, na atualidade, imperativos de existência. Ou seja, indubitavelmente o neoliberalismo transformou o que se entende como processos de inovação.

A construção de esferas de consumo com produtos que exibem valores intangíveis tem implicações para os pesquisadores que trabalham nos processos de inovação. Isto ocorre em função dos mercados que, cada vez mais, englobam consumidores que exibem conhecimento; e devido ao crescimento da exigência de processos de transparência nas informações, sobre como é realizada a produção e quais são as relações sociais nos locais onde são produzidos os objetos de consumo.

O neoliberalismo no desenvolvimento das economias globais de consumo estabeleceu novas conexões entre as múltiplas atividades e processos sociais que materializam e relacionam um produto a um dado local. Nesse sentido, entender a inovação neoliberal apenas como um perigo para o que tradicionalmente se entende como unidade de produção camponesa e/ou de mão de obra familiar é uma perspectiva que precisa ser revista, na medida em que pode assumir uma posição analiticamente conservadora, marcadamente ideológica e anticientífica. Igualmente duvidoso pode ser o posicionamento de que inovar é uma espécie de panaceia contemporânea, que resolverá toda ordem de problemas dentro das próprias esferas de consumo.

As inovações contemporâneas devem abordar problemas como aliviar a pobreza rural, alcançar crescimento econômico com base agroflorestal e alimentar sustentáveis, com atenção à emergência climática com justiça social e ambiental, assumindo, que a inovação nos territórios adquire importância e relevância social (ver, WORLD BANK, 2006; RAJALAHTI et al., 2008).

Se reforça com isto que o importante nos estudos contemporâneos do espaço rural é descrever e analisar as novas relações estabelecidas entre pequenos produtores, em termos de incorporação em grupos, redes e cooperativas, bem como transformações nas relações de gênero nas unidades domésticas de produção. Examinar qual o efeito sobre a força de trabalho, sobre a geração de empregos nos territórios e as ações de cuidado em termos sociais e ambientais, considerando empiricamente as múltiplas maneiras agroecológicas de produção vis-à-vis o avanço das formas convencionais. Em outras palavras, estudar casos de inovação contemporânea tem menos a ver com o descobrimento ou criação de novas invenções, e mais com o reposicionamento dos elementos existentes, evidenciando atividades e processos que tornam visíveis as propriedades intangíveis dos objetos e os relacionamentos estabelecidos com atores não necessariamente ligados à agricultura ou ao rural, e com redes que redefinem o direito, o acesso e o cuidado dos recursos naturais. 


\section{Alguns aspectos sobre a transição do sociotécnico ao sócio material}

Em contraposição aos espaços que se constroem e se destroem de forma criativa no mundo neoliberal Schumpeteriano, as inovações sócio materiais se constituem como espaços ambíguos de mudança, nos quais, de uma forma imperceptível, se aceita a existência do mercado, mas também se forja uma multiplicidade de reconfigurações e de relações sociais. Em tais espaços, as ideologias econômicas e políticas imperantes são confrontadas, direta e indiretamente, com as especificidades do poder e dos mundos modernos, onde os atores existem e esperam que as inovações cheguem e melhorem as condições de suas vidas.

Dito de outra forma, é na materialidade dos processos de mudança que a apropriação da linguagem, símbolos, valores e práticas dos atores finalmente associam a modernidade com o tradicional e o mercado, em um encontro de conhecimentos que ocorre cotidianamente na vida e experiência das pessoas que habitam estes mundos de existência.

É na materialidade do social que ocorre a interconexão global e local, como expressão das práticas, alianças, lutas, contradições e conflitos, que nos faz repensar criticamente a composição sócio material dos mundos de existência. Neste sentido, dar importância às práticas, objetos e entidades que compõem tais mundos, nos permite começar a reorientar a visão exclusivamente sociotécnica da inovação para uma perspectiva sócio material.

É a justaposição do moderno e do tradicional que nos leva a reconhecer o significado das relações e conexões parciais nos processos de inovação (neste sentido ver, STRATHERN, 1991; ARCE e LONG, 2000). As ideias, representações e práticas dos atores, no que se constitui como um desenvolvimento territorial, indiscutivelmente se inter-relacionam às políticas públicas e às estratégias dos especialistas. Também, as instituições (presentes ou não no território) constantemente tentam orientar a direção das transformações territoriais, no entanto, estas intervenções - diretas ou indiretas - nunca serão totalmente simétricas e/ou integradas às ideias, representações e práticas dos atores na forma de um regime sociotécnico. ${ }^{3}$

Desde uma perspectiva que mantém a centralidade no ator, a inovação se apresenta, na atualidade, como um espaço sócio material ambíguo e contraditório (ARCE e LONG 2000) e semi-autônomo (MOORE 1973), onde o desenvolvimento territorial se processa como uma série de cursos de ação ${ }^{4}$, heterogêneos em suas formas de conhecimento, e com uma grande variabilidade de como se constituem os

\footnotetext{
3 O termo regime é utilizado em lugar de paradigma ou sistema, referindo-se a 'regras', não somente regulações (formais ou não), mas também regras no sentido de papéis e práticas que estão sendo estabelecidas e que não são facilmente dissolvidas (KEMP et al., 1998). Geels (2004, p. 905) propõe o uso do termo 'regime sociotécnico' para designar o conjunto de regras semi-coerentes que interliga distintos regimes (i.e., tecnológico, científico, de mercado, sociocultural, político), tecnologias e produtos, estabilizando rotinas levadas a cabo pelos atores. 4 Cursos de ação descrevem práticas dos atores, que podem ser resultado de suas próprias estratégias de ação (MOORE, 1973) e/ou um resultado ambíguo (ARCE e LONG, 2000) do processo de implementação de projetos de desenvolvimento. Eles podem gerar processos de negociação, conflito e/ou aceitação das propostas do desenvolvimento e, não raro, eles correspondem à transgressão de normas socioculturais existentes ou ao surgimento de agendas de transformações territoriais. Nestes processos, os próprios atores adotam geralmente 'contra-tendências' às agendas desenvolvimentistas. O estudo das contra-tendências evita abordar o desenvolvimento exclusivamente como um processo de natureza geográfica e/ou administrativa, que incorpora a população e os territórios às formas políticas dominantes de organização social e econômica.
} 
produtos/mercadorias que circulam em mercados diversos. Estes produtos territoriais com valor de mercado, muitas vezes, começam a circular em mundos de vida longínquos, e aqueles que passam a consumi-los começam a dar forma e lugar a cenários de inovação sócio material, o que potencialmente escapa à preocupação institucional pela instrumentalização da regulação de políticas públicas (como se verá mais adiante no conflito entre o artesanal e o industrial no caso do Merkén). Em outras palavras, ambos, produtores e consumidores destes 'novos' produtos, escapam de possíveis regimes sociotécnicos que ordenam ou buscam estabilizar as formas de produção e circulação de objetos agroalimentares.

Os resultados desta inovação 'sócio material' constituem espaços ambíguos, onde uma multiplicidade de atores competirá para gerar uma 'realidade de mercado' do produto territorial, tornando a mudança social difícil de predizer. É assim que os estudos das inovações sócio materiais devem contestar as posições ideológicas (neoliberalismo) e instrumentais (mercado), na medida em que presumem a existência de certas trajetórias de desenvolvimento territorial, que ocorreriam 'automaticamente' por meio do acesso ao mercado.

Descrever e analisar, na América Latina atual, estas experiências de inovações sócio materiais, utilizando as cadeias de comercialização e a agregação de valor, adquire importância para entender transformações territoriais, nas quais regimes sociotécnicos são substituídos pela revalorização de processos situados localmente (ver, OYARZÚN, et al., 2013). Pode ser conveniente lembrar que, no contexto dos estudos sobre inovação, normalmente, o foco está colocado sobre as novas tecnologias, porém, ao identificar e valorizar outros processos territoriais, abre-se possiblidades de renovar perspectivas sobre espaços relevantes para as mudanças sociais, sem deixar de considerar as potencialidades e problemáticas tecnológicas. Nesse sentido, são os diversos encontros de conhecimentos, as interações dos diversos atores entre si, os mercados e as materialidades que estão gerando novas formas de inovações, localmente situadas, tendo como eixo o mercado e a valorização global da 'tradição'. Tais inovações se manifestam nas unidades de produção camponesa, nas estações experimentais, nos dispositivos do agronegócio, nas cooperativas de mulheres, entre minorias étnicas de um território, mas também, em coletividades de práticas territoriais e uma multiplicidade de associações de consumo (ver, BLANCO et al., 2017; e CHARÃO-MARQUES et al., 2017).

A 'inovação' cada vez mais, faz parte habitual do discurso acadêmico e institucional. As universidades investigam e oferecem cursos, proliferam incubadoras tecnológicas com esta finalidade, os governos criam centros de pesquisa e fundações, nos quais recursos financeiros - públicos e privados - se combinam promovendo mudanças na valorização de produtos com atributos específicos, locais ou territoriais. No que tange aos produtos agroalimentares de interesse gastronômico ou nutritivo diferenciado, a inovação pode responder a uma visão de desenvolvimento territorial que promove certa 'tradição' bio-cultural. E, neste sentido, ela pode corresponder a inovações sócio materiais que valorizam produtos patrimoniais protegidos mediante a Indicação Geográfica (IG) e as Denominações de Origem (DO).

Todavia, a valorização comercial do patrimônio alimentar gera também certos problemas, estes são, dentre outros, a desterritorialização dos alimentos, um despojo parcial do conhecimento local e uma transformação dos espaços comerciais de circulação e de consumo anteriormente conhecidos. A institucionalização das 
indicações geográficas, denominações de origens e certificações, geralmente, são processos que tentam impedir a formação de múltiplos centros de autoridade sobre um território, e justamente por isto se tornam processos cheios de contradições e incertezas. Considerar estes problemas nos instiga a aproximar-nos criticamente à 'inovação', em especial, dando maior atenção aos processos que fazem emergir novas formas de organização social, que tenham potencial de distribuição do poder e/ou de renovar as relações de autoridade, este enfoque é fundamental para repensar o que entendemos por inovação sócio material.

\section{Trajetória de uma inovação sócio material 4.1 Merkén: um picante artesanal}

As origens do Merkén estão localizadas no processo artesanal de sua produção, e nos padrões de consumo que o caracterizam como um condimento 'especial'. De cor cobre avermelhada, é um pó de gosto defumado e ligeiramente picante, obtido da desidratação de diferentes variedades de pimenta, que é utilizado para temperar comidas principalmente na região sul do Chile, zona que vai de Chillán a Araucanía.

Este condimento, nos últimos 30/40 anos, alcançou celebridade gastronômica nacional. Atribuído ao saber culinário Mapuche 5 , e com uso disseminado nas cozinhas populares, passou por um processo que foi denominado o desenvolvimento de uma 'nova culinária chilena pós ditadura' (AGUILERA, 2016). Isabel Aguilera sugere que o resgate do 'Merkén Mapuche', não deve ser interpretado como uma expropriação, mas como uma 'apropriação', que torna visível os Mapuches, fazendo parte de um movimento culinário que reconhece o valor da cozinha popular.

Esta incorporação do 'mapuche' à cozinha chilena se dá mediante um entorno multicultural e de mercado, no qual a comercialização do diverso está interconectada com a identidade nacional, uma espécie de síntese de "la chilenidad" (AGUILERA, 2016). O Merkén passa a aparecer como um produto industrial, gourmet e também de registro de uma identidade nacional diversa, que comercialmente está sendo incorporado com êxito aos produtos da chamada 'marca-país'.

No entanto, o Merkén artesanal, como produto emblemático de atores que vivem de suas hortas familiares, é uma janela para apreciar as transformações que sofreu a pimenta (el ajî), os preparados de pimenta e o Merkén, em localidades como a comuna de Santa Juana. Ali, a horticultura é importante. ${ }^{6}$ As pimentas são demandadas por consumidores de hortaliças frescas que conhecem a reputação da comuna. Os produtores vendem sua pimenta em 'capi' verdes, em tranças ou na modalidade em pó, desidratado e defumado (el Merkén). As variedades de pimenta (ecotipos) reconhecidas e classificadas pelos produtores por sua pungência são: 'puta madre' (provavelmente, Capsicum chacoense), 'cacho de cabra' e 'huaipe' (Capsicum annuum).

Os produtores selecionam os melhores frutos para obter suas sementes, estas são extraídas depois de secas e guardadas em latas ou frascos de vidro. As pimentas

\footnotetext{
5 Grupo étnico originário, que vive em territórios que, hoje, correspondem ao Chile e à Argentina.

${ }^{6}$ Os produtores mencionam que, a partir dos anos 1970, o fechamento das minas de carvão de Lota e Coronel gerou uma forte quebra na demanda do "ají verde en capi" (e outras hortaliças). Este evento levou os produtores a darem mais importância ao processo de conservação (desidratados), transformando o Mérken, paulatinamente, em uma fonte de renda importante para as famílias horticultoras.
} 
começam sua vida em sementeiras, sob proteção de túneis plásticos, devido às geadas. A prática de produção de mudas é importante e começa em agosto. Apenas em novembro, é feito o transplantio para os canteiros, onde os agricultores tentam combinar aproximadamente $1 / 3$ de cada ecotipo. Eles explicam que o objetivo é garantir a variabilidade de pimentas, de maneira manipular o picante e a cor (sabor e aparência) do Merkén de Santa Juana.

O cultivo da pimenta se realiza principalmente com mão de obra familiar, com ajuda da família ampliada (irmãos e primos) e das famílias vizinhas. ${ }^{7}$ As relações e práticas de trabalho são importantes fatores na constituição dos grupos familiares assentados no território. Estes dão vida às localidades, emprestando muitas vezes os sobrenomes aos diversos espaços intracomunitários (por exemplo, 'Castro', 'Yañez', etc.), por sua vez, estes são identificados com a receita de dado tipo de Merkén.

A colheita começa em fins de março. A pimenta verde (capi) se vende nos mercados e feiras regionais. Os produtores dizem que o ponto de atenção está em evitar que a pimenta passe de uma consistência firme a uma macia, porque, quando isto acontece, "el ají se apolilla" (apodrece), "y no se puede usar para el Merkén". O momento ótimo para a colheita ${ }^{8}$ se dá por uma leitura da cor dos frutos. De acordo com os produtores, quando a metade das pimentas cultivadas têm uma cor vermelha profunda (maduros), e o resto um tom avermelhado (pintado) se pode começar a colher. Finalmente, todas as variedades devem ser colhidas antes que comecem as chuvas. Durante a colheita, frutos grandes (cacho de cabra e huaipe) são separados dos pequenos (puta madre), que são os mais picantes. Esta seleção é importante, porque é a combinação de variedades que confere a cor e entrega mais ou menos pungência - sensação de ardor - ao Merkén que cada um produz.

A técnica da defumação conserva por mais tempo um alimento, sendo uma prática culinária que consiste em expor os alimentos à fumaça de fogões ou braseiros, onde se queima a lenha para desidratar os frutos - é esse contato com a fumaça que vai conferir especial cor e sabor ao ají. As plantas colhidas ou os "cachos" de frutos são pendurados na "zaranda"9. Alguns usam dois períodos de defumação, outros realizam a prática "del secado del aji", que consiste em tostar os frutos diretamente em uma chapa metálica ou em forno de barro. Doña Claudina descreve a mudança processo:

\begin{abstract}
Mi mamá tenía una callana [peneira de metal] grande, después las personas empezaron hacer canastos de mimbre, estos eran colgados sobre el fuego y se iban moviendo, dando vueltas, para que el ají se tostara bien. Ahora yo tuesto el ají en horno de barro. Este me lo construyo mi hermano hace tres años para hacer pan, y yo me dije si este horno sirve para hacer pan, ¿porque no me puede servir para secar el ají? [... L La ventaja de tostar el ají en el horno de barro, es que uno no respira el humo picante que se desprende, cuando el ají se tuesta en la callana o en los canastos es bien contaminante. Por esto yo digo, que el tostado de antes, no es igual a como lo hacemos ahora. [Notas de campo, 14/08/2018]
\end{abstract}

\footnotetext{
7 É comum a realização da 'minga', que corresponde a um 'mutirão', no qual o trabalho não remunerado - afetivo - reforça as relações de parentesco com vínculos de amizade.

${ }^{8}$ Os produtores podem colher a planta inteira (com ou sem raiz) ou apenas os frutos. Esta última modalidade, eles recomendam quando não se tem muitas plantas para defumar.

9 Zaranda é uma espécie de treliça de madeira, que fica suspensa no teto, na qual ganchos de metal são usados para sustentar as plantas durante o processo de defumação. Algumas "zarandas" estão em peças especiais - salas de secagem -, outras seguem nos tetos das cozinhas das casas, mas cada vez menos, na medida em que a demanda pelo produto aumenta.
} 
As diferentes técnicas aumentam o calor direto para extrair o resto de umidade, e conferem aos frutos uma cor lustrosa e uma consistência crocante. Estas práticas sumamente artesanais dependem do conhecimento e da experiência sensorial dos produtores, e são as que permitem ressaltar a cor cobre-avermelhada e os sabores das pimentas, antes de que os frutos sejam moídos e misturados.

Lo más difícil fue aprender cuanto es el calor que se necesita para tostar el ají. El horno tiene que calentarse con leña y la temperatura hay que calibrarla, esto no es fácil, pero experimentando se aprende, ahora ya sé. Cuando toco las paredes del horno, y el barro se siente caliente, es que puedo comenzar con el tostado. Entonces, saco del horno las brasas y lo dejo bien limpio, para introducir y acomodar el ají sin su colita [pedúnculo], y con las pepitas [semilla]. Lo hago así porque el ají rinde más (más provecho, rendimiento) cuando lo muelo, y queda picosito. (DOÑA CLAUDINA, notas de campo, 14/08/2018).

É fundamental entender, aqui, que os sabores singulares de cada Mérken dependem sensivelmente de como se utilizam essas técnicas, do tempo que os frutos ficam na zaranda e assim por diante. Das notas de campo [obtidas em 14/08/2018] se extraem algumas ilustrações de outras expressões sócio materiais relacionadas à obtenção do Mérkén. Doña Inés explica:

También es importante saber acomodar las plantas y los frutos en la zaranda. El poder mover las plantas es fundamental [...] una vez que se acomoda la base de la zaranda con algunas plantas, las otras plantas deben colocarse paradas, para así facilitar que las plantas se puedan mover, para que estas reciban el humo en conjunto.

Don Carlos também ensina: "Con la utilización de las tijeras de podar, dejamos la raíz y parte del tallo en el huerto, y esto favorece que el ahumado se de en forma homogénea. Si esto no sucede, el ají comienza a cubrirse de hongos, y se malogra."

Doña Sofía complementa:

Si la leña no calienta mucho el ají se demora más en secarse. La leña de eucalipto y del aromo son buenas, porque estas son más calurosa, y secan más rápido. Lo importante de saber elegir bien la leña, es para producir una buena cantidad de humo, pero no mucho calor. [... L La madera de pino es buena, pero es ahumadora de más. La resina al quemarse da un humo muy pesado, el hollín se pega y el ají se pone negro, el ají queda coloradito, pero queda más oscurito y con residuos de la resina. Esto afecta el sabor del ají que queda con un gusto bien diferente. [...] Antes se ahumaba con maderas nativas como de los arrayanes, avellanos y condihueñas, pero estas se acabaron. Se terminaron, porque las fueron talando y después se colocó todo de pino. La diferencia del ahumado es más cuando la leña está húmeda, el ají quiere humo pero no ese humo pesado.

A fumaça transporta partículas que tornam difícil a respiração das pessoas, especialmente durante o inverno, e provoca o acúmulo de fuligem negra (el hollín) nos frutos e nas salas de secagem, e pior quando é dentro das casas das famílias. É a combustão incompleta da lenha que produz a fumaça para defumar as pimentas, assim, seu manejo é importante. Sobre isto Don Carlos diz:

Lo mejor para ahumar, son las construcciones con techos de tejas [de barro], esto porque el humo puede salir, donde comienzan los problemas es cuando se ahuma en lugares con techos de pizarreño y zinc, porque estos techos más modernos no dejan salir el humo tan fácilmente. 
Finalmente, o processo de moer e mesclar o ají também é importante. Don Mario conta:

\begin{abstract}
Antes los ajíes se molían a mano en un mortero de piedra, después se hacía con un molinillo a mano, esto era cansador y se respiraba mucho el polvo, ahora se muele con el molinillo de mano adaptado para que gire con electricidad. Esta nueva modalidad fue una innovación que se realizó aquí en la comunidad por productores que hicieron funcionar el molinillo con motores eléctricos y cadenas de bicicleta. Algunos productores utilizan molinillos de martillo, y estos dejan el Merkén menos molido.
\end{abstract}

É sofisticado o conhecimento que leva a produzir as mesclas características dos diferentes 'gostos' - identificações singulares relacionadas às receitas das diferentes famílias - adquiridos pelo produto, embora, os processos sofram transformações na medida em que a demanda vai aumentando. Os produtores dizem que, hoje em dia, a pungência do Mérken se aumenta adicionando "el puta madre", mas eles afirmam que começaram a usar esta variedade somente nos últimos 30 anos. Anteriormente, de acordo aos produtores, a variedade puta madre não se usava em Santa Juana. Alguns dizem que o Merkén não se deve mesclar com nada e a pungência se adapta como cada um queira consumir. Porém, há intermediários que demandam um produto muito picante, de modo que eles mesmos baixam a intensidade com outras misturas. Entre os produtores, apenas um combina o Mérkén com sementes de coentro.

Os produtores nos permitem perceber que a 'materialidade gastronômica' do Merkén está profundamente relacionada às formas de cultivo e a conhecimentos refinados desenvolvidos localmente sobre a defumação, a moagem e as mesclas, o que particularmente é difícil de replicar em um processo de padronizado industrial. Por outro lado, o Merkén seguiu o caminho de outros produtos agrícolas locais, com o aumento do consumo gastronómico e do seu valor agregado. Esta é uma estratégia de valorização comercial que sugere uma forma neoliberal de inovação sócio material, ao ativar espaços rurais deixados de lado pelos agronegócios empresariais. Esta inovação neoliberal afetou de maneira significativa a autonomia política das chamadas unidades familiares de produção, principalmente, através de sua incorporação a mercados emergentes que demandam culinárias específicas, exigindo uma sensorialidade pelo exótico e a diferenciação com relação a outros produtos similares que circulam no mercado. Alguns aspectos desta transformação serão abordados a seguir.

\title{
4.2 A gastronomia do ají, o étnico, a agregação de valor e a empresa
}

A estratégia de agregar valor aos produtos locais não é recente. A busca de produtos culinários especiais para incrementar seu valor tem sido uma orientação do processo mundial denominado 'a globalização e a reorganização do valor dos alimentos' (ver alguns casos, ROSEBERRY, 1996; BESTOR, 2000; FREIDBERG, 2003). A importância mundial do vinho chileno é um caso bem conhecido, com relação à formação de cadeias de valorização e consumo global de produtos nacionais (ver GOLDFRANK, 1994), e do seu custo social, à paisagem do espaço rural e à força de trabalho (ARCE e MARSDEN, 1993).

No Chile, a circulação do Merkén no mercado nacional e internacional como produto 'gourmet e saudável' vem sendo celebrado pela chamada nova cozinha 
chilena, e recebeu aclamações do movimento Slow-Food. ${ }^{10}$ O Merkén, como produto territorial, tem sido mobilizado por 'novos empreendedores', chefs e movimentos globais de alimentação, convidando o consumidor a degustar aromas e sabores com um sentido cultural, histórico e técnico. Frente a este entusiasmo com o condimento, várias empresas começaram a desenvolver produtos similares ao Merkén, tentando replicar os processos artesanais da produção, incorporando tecnologia industrial à confecção do 'produto patrimonial'.

É neste espaço de inovação comercial de um produto territorial que as potencialidades de alto valor gastronómico geram contradições sobre a 'autenticidade' e a 'identidade', entre as formas de produção industrial, semiindustrial e a artesanal. A perda da integridade que identifica um produto com seu território é, em parte, resultado das vantagens que o mercado oferece. No caso do Merkén, este provém de uma cultura ancestral Mapuche, no mercado, se encontram recipientes bem desenhados e sofisticados, que enfatizam a narrativa do vínculo com o étnico e o autenticamente Mapuche. O apelo do 'exótico', como constituinte de atributo específico, é sintomático do mercado, no qual o Mérken conquistou um espaço privilegiado como um produto gastronômico inovador, em um contexto de alta competividade dos negócios com condimentos. Assim, nos últimos vinte anos, a gastronomia chilena vem experimentando com produtos gourmet e com os condimentos, 'reeducando' paladares dos consumidores.

"Merkenes" de origem semi-industrial e industrial surgiram nos últimos tempos. Esse desenvolvimento foi favorecido por estudos de mercado realizados por entidades como o ProChile ${ }^{11}$, que, visando diversificar produtos para exportação, aponta para 'nichos de valor' de produtos de consumo 'sofisticados'. Neste sentido, o Merkén artesanal apresenta, como produto, a vantagem da distinção, devido à herança biocultural associada. As práticas territoriais (seleção de sementes, produção de mudas, defumação, tostado, moagem e receitas específicas), conferem a Merkén uma vantagem como produto regional da Araucanía, que é justamente atributo que ajuda impulsionar o mercado. Paradoxalmente, o mercado Merkén está deslocando e subordinando politicamente o Merkén artesanal.

No Chile, existem quatro marcas líderes no mercado de condimentos, que dividem 90\% das vendas, são: São "Marcopolo", do ICB, "Gourmet", "Sabu", de Velarde Hermanos e "Surco", de Elabal (Diario Estrategia, 2004). Três dessas quatro empresas apresentam a pimenta Merkén, como parte de sua gama de produtos diferenciados (Gourmet, Velarde Hermanos e Elabal). As empresas internacionais mais proeminentes são 'Gourmet Chileno' e 'Chili from Chile'. A pimenta desidratada é a matéria-prima de uma gastronomia industrializada, que a utiliza na forma de pó e flocos, para a preparação de molhos, picles e extração de pigmentos naturais.

O Merkén difere das pimentas em pó genéricas por suas características organolépticas especiais (cor, sabor e aroma) associadas ao seu método de elaboração (artesanal) e seus ingredientes específicos (variedades de pimenta e, em alguns casos, mesclas com outras especarias). Isso é demonstrado pelo nosso trabalho de campo e pelo estudo da FAO (OYARZÚN et al., 2013). É importante destacar que a produção artesanal e semi-industrial de Merkén ainda é a

\footnotetext{
10 Ver: https://slowfoodenchile.files.wordpress.com/2014/05/spa_libretto_merken.pdf

${ }^{11}$ Instituição do Ministério das Relações Exteriores encarregada de promōor bens e serviços com potencial para exportação, por meio da internacionalização de empresas chilenas, da promoção da imagem do país, do investimento estrangeiro e do turismo. Detalhes em: https://www.prochile.gob.cl/
} 
predominante, mas a indústria gastronômica começa a tentar replicar as práticas de elaboração de condimentos, iniciando um processo de deslocamento dos produtores locais ou, em outros casos, inicia um processo de integração vertical dos produtores que, antes, o produziam em seus territórios.

De acordo com projeto de fomento à inovação ${ }^{12}$, iniciado em 2006, a heterogeneidade do 'produto merken' é o resultado da apresentação da pimenta Merkén no mercado e dos canais de comercialização utilizados para distribuição. Quando se trata de canais informais, o produto chega ao consumidor através de pequenas empresas, não apresenta rotulagem e não corresponde a uma apresentação uniforme, sendo vendido, preferencialmente, em pequenos sacos plásticos e com preços variáveis. Aparentemente, 70\% do Merkén vendido nesses mercados 'informais' vem da Região VII (Região de Maule). Quando se trata de um circuito formal, a apresentação é em saquinhos de 15 gramas, o preço varia de acordo com seus ingredientes, recipientes e preparações (conservantes químicos). Merkenes que são produzidos com um nível mais alto de industrialização (moagem industrializada) têm os preços mais baixos, e são fabricados principalmente na região metropolitana de Santiago (capital).

Neste ponto, é importante destacar a experiência da empresa 'Chili from Chile', que foi capaz de entrar no mercado nacional e internacional, com uma ampla gama de produtos, através de uma estratégia comercial inovadora. A empresa optou pela venda de Merkén em pontos inovadores, como postos de combustíveis, restaurantes em rodovias e lojas em aeroportos. Perto da cidade de Los Angeles (Chile), uma indústria seca e defuma as pimentas, que chegam da região produtora em bolsas de grande volume. Depois de processado, a empresa finalmente o entrega o Merkén como produto final para seus distribuidores e intermediários.

Esta empresa firma contratos com alguns produtores, Ihes entregando sementes certificadas para que comecem os cultivos. Com isto, visa garantir a padronização da matéria prima que vai ser industrializada como 'Merkén' (CARVALLO, 2016). Este Merkén compete com aquele artesanal, e alcança sabores, cores e aromas que satisfazem parte dos consumidores de pimenta nacional e internacionalmente. A empresa com esse tipo de Merkén industrializado conseguiu fragmentar a oferta e a 'qualidade' do produto, gerando ambiguidades através da fabricação industrial de um produto territorial, além de gerar dúvidas sobre o que é o 'autêntico' do Merkén.

Contudo, a indústria de condimentos não é o único protagonista da inovação comercial dos produtos com identificação territorial, a tentativa de negociar e manipular a definição do Merkén Mapuche também inclui os chefs da nova gastronomia, especialmente no setor hoteleiro e de restaurantes de luxo. Esses 'novos' atores exercem importantes influências político-culturais no controle do processo patrimonial do Merkén. Os consumidores passam reconhecer como Merkén 'novos objetos' que constituem parte de um contexto gastronômico global, baseado em uma herança cultural e tecnológica em mudança; no qual há esforços

\footnotetext{
${ }^{12}$ Chamado de 'precursor', este foi um projeto de inovação em escala piloto financiado e promovido pelo FIA, tendo sido, implementado entre 2006 e 2009 na IX Região de La Araucanía, por iniciativa da Universidade Católica de Temuco, com a participação de produtores e processadores de Merkén, as empresas EMADIL Ltda. e Bruno Bertolotto R. Também, participaram, como agentes associados, o Serviço de Cooperação Técnica (SERCOTEC) e o Programa de Recuperação Ambiental e Desenvolvimento Sócioprodutivo em Áreas Rurais e Indígenas da IX Região de La Araucanía: “Araucanía Tierra Viva”.
} 
para evitar a dissolução das 'tradições alimentares', todavia, promovendo sua folclorização, de maneira a aumentar o valor comercial do Merkén, agora, como mercadoria industrializada, genérica ou de nicho de mercado.

A este fenômeno estamos identificando como 'gentrificação do Merkén' (Ver, ARCE e CORTÉS, 2019). Relacionado a ele está o aumento do consumo e intensificação da produção, o que causa sua desterritorialização e o transforma em um produto gastronômico comercial, que gradualmente vai perdendo sua relação material com as práticas territoriais da produção artesanal. Algumas iniciativas institucionais, como as do ProChile, incorporaram com sucesso o Merkén como um produto da chamada 'marca do país'. Onde se destaca como um produto com potencial de exportação. Essas táticas de inovação comercial passam contar com 'empreendedores', que são chamados a interagir com o Merkén, e isso se apresenta como uma aposta de negócio viável para exportadores e inovadores comerciais chilenos. ${ }^{13}$

A ambiguidade da inovação se manifesta em processos de desterritorialização e padronização do Merkén, que ora se apresenta como um 'produto genérico', ora como 'produto de nicho', no entanto, as duas situações afetam o produto territorial/patrimonial. De outra parte, a indústria de alimentos também usa o Merkén 'informal' como ingrediente em algumas de suas preparações. O Merkén artesanal está sendo comercializado, em todo o país, a granel, sem padronização e sem resolução sanitária; assim como, diretamente por pequenos produtores artesanais em mercados locais das cidades da região sul do país, e para restaurantes, hotéis e lojas gourmet em Santiago.

O aumento generalizado da demanda pelo Merkén, seja o artesanal ou o semiindustrial, acabou por valorizar o produto junto aos consumidores. No entanto, isso não interrompeu o processo de gentrificação do Merkén, com suas variantes de mercado industrial, genérico e de nicho, que continuam seus cursos, e nos entregam elementos empiricamente verificáveis de que há um aumento da ambiguidade dos espaços de inovação comercial de produtos territoriais.

\subsection{Desenvolvendo potencialidades de um produto territorial: algumas lições}

O processo de gentrificação do Merkén e a agressiva industrialização do produto pelas empresas chilenas de condimentos provocaram instituições, como as universidades, a iniciarem processos de inovação territorial e de comercialização. Um objetivo central era fazer com que a comunidade produtora passasse a ser partícipe da popularidade crescente do condimento, utilizando o potencial da pimenta como produto territorial indutor de desenvolvimento nas localidades.

$\mathrm{Na}$ área de Araucanía, Bío-Bío e Los lagos, destacam-se os esforços pioneiros da Faculdade de Agronomia da Universidade Católica de Temuco que, desde 2005, inicia um programa de inovação comercial do Merkén. O projeto de valorização do Merkén tinha por finalidade a exportação do produto para o mercado norte-

\footnotetext{
13 Os volumes exportados atingiram o máximo em 2008, com aproximadamente $3.200 \mathrm{~kg}$ comercializados. São $75 \%$ para os Estados Unidos, 27\% para a Comunidade Econômica Europeia, 3\% para a Ásia e 0,2\% para a zona econômica conhecida como ALADI. Finalmente, as empresas exportadoras com maior participação no mercado exportador, em 2009, foram a Chilean Gourmet (83\%); INTRANCO - F (15\%); ETNIA-F (0,7\%) e ICB-F (0,4\%) (FIA, 2010).
} 
americano. ${ }^{14}$ Este projeto, em sua segunda fase, em 2007, passa a contar com a colaboração da Secretaria Regional do Ministério da Agricultura (SEREMI Agricultura), a Fundo para a Inovação Agrária (FIA), o Instituto de Desenvolvimento Agrícola (INDAP) e o programa Araucanía Tierra Viva. Essas instituições se coordenam para desenvolver o potencial comercial do Merkén, nos municípios de Chol-Chol, Los Sauces, Purén, Lumaco, Temuco e Angol. A ideia principal era homogeneizar o produto (como mencionado, cada família produtora tem processo e receita próprios) pela instalação de seis plantas de processamento em pequena escala, e uma planta piloto para melhorar o processo de fabricação que, a médio prazo, deveria gerar uma produção em escala industrial.

Inovar, neste caso, foi visto como implantar certas técnicas para melhorar a produção e o processamento da pimenta de modo a incrementar seu valor e potencial comercial. O projeto tentou gerar uma oferta de Merkén de alta qualidade e aumentar os volumes para atender à demanda dos mercados internacionais. $O$ projeto tinha como pano de fundo a recuperação ambiental e o desenvolvimento sócio produtivo em áreas camponesas e indígenas. Outro objetivo era obter a denominação de origem, e assim, apresentar um produto "premium" aos mercados, além de desenvolver uma oferta de produtos desidratados típicos da cultura Mapuche. A diretora do projeto diz: "Estamos enfocados a desarrollar tecnología con el ecotipo local de ají cacho de cabra, propio de la agricultura Mapuche con un color rojo intenso y alto sabor picante que lo hacen un producto único." (GINA LEONELLI).

O Merkén de exportação seria enviado aos Estados Unidos, apoiado pelo FIA, através da empresa Chilean Gourmet, que usaria sua própria marca - Merkén Chileangourmet -, enquanto o óleo aromatizado com a pimenta - Kultrun Chileangourmet - também entrou no portfólio da emrpesa. Ambos os produtos foram lançados oficialmente no mercado gourmet dos EUA, durante a Fancy Food Show em Nova York, onde, em 2007, a empresa expôs no pavilhão chileno.

Embora este projeto de inovação tenha uma orientação clara de comercialização para o mercado de exportação, seu sucesso foi reduzido. O projeto da Universidade Católica, ao defender a necessidade de obter a indicação geográfica e, posteriormente, o selo de origem para o Merkén como um produto patrimonial Mapuche, abriu uma janela importante para identificar o condimento como parte da culinária deste grupo étnico. Assim, provoca uma reavaliação cultural do Merkén, principalmente no que se refere a sua diferenciação da produção industrial de pimenta moída na região central do país (FIA, 2010), e também um repensar sobre as empresas que o gentrificaram, transformando-o em um produto gourmet para o mercado nacional e internacional.

A indicação geográfica (ou a denominação de origem) nunca se concretizou, porém, o projeto da Universidade Católica de Temuco foi relativamente importante, e teve desdobramentos, por exemplo, na FAO, em um conjunto de estudos sobre produtos patrimoniais na América Latina. ${ }^{15}$ Também, para o grupo da Universidade do Chile (Faculdade de Ciências Agronômicas) o projeto 'piloto' serviu de estímulo, desencadeando outro projeto de inovação, já em 2017, também com apoio do FIA, porém, mais específico.

\footnotetext{
14 Ver: http://noticias.universia.cl/vida-universitaria/noticia/2007/07/23/320191/productores-merken-reunen-uct.html 15 Tais estudos acabaram por desenvolver a metodologia do 'ciclo virtuoso de inovação de produtos territoriais', que foi aplicada em cinco casos de estudo na América Latina (ver, (OYARZÚN et al., 2013).
} 
Esse projeto - Merkén de Santa Juana: valorización de Recetas Ancestrales y Rescate de Ajíes Locales $^{16}$ - encontrou enquadramento na linha de Resgate e Valorização do Patrimônio Agropecuário e Florestal do FIA; e visava fornecer apoio técnico e econômico a inovações que viessem a revitalizar a prática de produzir o Merkén na comuna de Santa Juana ${ }^{17}$, valorizando o potencial do desenvolvimento territorial e a importância cultural do resgate de pimentas locais. Com o apoio do município e uma equipe técnica da Faculdade, reforçou-se o trabalho que já vinha sendo realizado pelo INDAP, através do PRODESAL ${ }^{18}$ e das agrupações camponesas da comuna. A proposta foi promover o resgate das receitas locais da preparação do Merkén e demonstrar que o produto de Santa Juana é único e que, portanto, a prática cultural do ají patrimonial precisa de uma revalorização sócio material.

Parcelas demonstrativas foram estabelecidas para estudar os pontos críticos do manejo agronômico para, em seguida, estabelecer uma sala de processamento, na qual os pequenos produtores poderiam ter um local para preparar a pimenta e começar com a etapa de padronização das receitas. Essas ações foram entendidas como parte de uma "iniciativa biocultural”, que precisava ganhar visibilidade para ser reconhecida no mercado nacional e internacional. Com a implementação do projeto se percebia que muitos produtores estavam mais interessados na visibilidade que 0 projeto Ihes daria, e menos nas potenciais contribuições técnico-produtivas. A expectativa deles era adentrar, finalmente, no mercado gourmet; isto significava deixar de vender o produto a granel, e contar com embalagens com design atrativo, com licença sanitária e rótulos com informações nutricionais e culinárias adequadas.

O projeto, que foi concluído em 2019, teve uma primeira etapa que visava verificar possíveis diferenças ecotípicas entre as pimentas cultivadas em Santa Juana, como parte da avaliação da viabilidade biocultural do Merkén. A segunda etapa, passou resgatar histórias e receitas do Merkén juntos às famílias que o produzem, tendo foco a recuperação do patrimônio alimentar. Ao contrário do projeto da U. C. de Temuco, cujo objetivo era aumentar volumes de produção para viabilizar a exportação, o trabalho em Santa Juana buscou estabelecer um produto típico da localidade, porém, com a preocupação de promover a adequação sanitária, por isso, a ideia da sala especial para processamento e embalagem.

Os camponeses de Santa Juana gozam de boa reputação como horticultores em função da qualidade dos seus produtos, e a comuna está posicionada com sucesso na produção 'autêntica' de Merkén. Ao mesmo tempo, os produtores, devido ao seu conhecimento dos mercados regionais, em especial da região metropolitana de Concepción, têm bem estabelecidos seus canais de comercialização, quem são seus compradores, inclusive os intermediários comerciais, o que beneficia a distribuição das suas pimentas e do Merkén. Nesse sentido, o resgate sócio material do 'Merkén patrimonial', principalmente na dimensão biocultural do projeto de inovação, contou com o apoio das diversas famílias

\footnotetext{
16 Ver: http://www.fia.cl/fia-promueve-rescate-de-emblematico-merquen-de-santa-juana/

${ }_{17}$ A comuna de Santa Juana foi identificada em um estudo exploratório da Universidade Católica de Temuco, ainda em 2012, como a localidade que produziu a maior quantidade de Merkén na região de Bío-Bío.

18 Programa de Desenvolvimento Local (PRODESAL), junto com o Programa de Desenvolvimento Territorial Indígena (PDTI), são parte dos Programas Territoriais do INDAP - Instituto de Desenvolvimento Agrícola. Funciona mediante acordos ou contratos entre o INDAP e as entidades executoras, como municípios, ou outras entidades públicas ou privadas. Desde 2015, Santa Juana conta com programa do PRODESAL, com objetivo de organizar cerca de 600 famílias de camponeses para melhorar a qualidade de frutas e hortaliças, com a finalidade de acessar mercados na região metropolitana da Grande Concepción.
} 
produtoras. No entanto, os produtores foram enfáticos sobre a manutenção das receitas de cada uma das famílias, e foram firmes ao afirmar que não mudariam suas formas de comercialização e acesso aos mercados regionais.

Para os produtores, a luta por estabelecer-se no mercado foi longa. Falando especificamente do Merkén, trata-se de um mercado que foi transformando-se há gerações, desde o tempo em que os compradores de ají eram os trabalhadores do setor da mineração de carvão nos mercados de Lota e Coronel até a década de 1970, quando as minas são fechadas. Em outras palavras, a vida social do Merkén no território, eventualmente, se manifesta como uma dimensão semiautônoma, uma vez revelada a importância que as estratégias próprias de produção e comercialização tinham para os produtores, e eles reivindicaram, desde o começo do projeto de inovação, que elas fossem respeitadas.

Uma das propostas do projeto era estabelecer a planta coletiva de processamento. Os argumentos de alguns produtores contra essa ideia eram de que o processamento deixaria de ser feito nas casas e a planta estava um pouco afastada, o que obrigaria ter que se deslocar com as pimentas até o local centralizado. Isto lhes criaria um problema logístico, levaria mais tempo e aumentaria o custo do produto. Outros argumentavam que o uso coletivo da planta criaria problemas de contaminação, em função das misturas das pimentas de várias procedências. Além disto, a planta coletiva exigiria regularidade no volume da pimenta para secar e embalar, e isso, segundo alguns produtores, afetaria profundamente o processo de tosta das pimentas (finalização do produto), o que iria arruinar as receitas familiares do Merkén, gerando conflitos entre os produtores, e entre eles e seus compradores. Aqui, talvez o mais importante, é que estaria em risco certos atributos do ají-merkén que contribuem para garantir a integridade de um produto identificado com 0 território.

O entendimento das famílias de que as receitas singulares deveriam ser mantidas se mostrou como parte fundamental do processo de revalorização do condimento Mapuche, sendo algo que o projeto não poderia transformar. Desta forma, a maior fortaleza do projeto de inovação era contribuir para dar visibilidade ao conhecimento e capacidade dos atores em desenvolver os novos espaços, onde os produtores poderiam manobrar seu reconhecimento como "merkeneros", constituindo redes institucionais e de consumidores, facilitando para eles a troca comercial do condimento.

É importante sublinhar que a ênfase no resgate sócio material da 'realidade' dos ají-merkén estabelece um diferencial importante nesse projeto de inovação, com relação ao precursor, desenvolvido em outras regiões. O projeto da U.C. de Temuco enfatizou as melhorias nas características técnicas do produto, com o objetivo principal de penetrar o mercado norte-americano de condimentos. O projeto da $U$. Chile apostou em uma orientação sócio material e do ator, enfatizando a capacidade dos produtores nas definições de objetivos e estratégias (de mudança ou não) no processo de produção e comercialização do Merkén. Com o objetivo de propiciar que eles próprios exercessem suas decisões e poder em relação a outros atores e interesses, na medida do possível, se estabelece a possibilidade de um processo mais democrático de inovação territorial. Isto exigia a compreensão da relação biocultural entre os atores sociais e o ají-merkén. Destacam-se o conhecimento das variedades (ecotipos), seu cultivo e combinações, além do detalhado manejo da fumaça. Ou seja, era necessário entender sociológica e antropologicamente qual era o impacto dessa 
materialidade na constituição individual dos produtores e nas memórias coletivas como 'produtores Merkén de Santa Juana'.

É assim que uma das lições do projeto da U. do Chile foi entender que a inovação comercial, por mais importante que seja, não constitui a avaliação mais importante do específico e autêntico na produção artesanal da Merkén (receitas familiares). No entanto, isso implica no desafio de deixar de lado normas padronizadas para concentrar-nos na organização social e material do produto territorial, reconhecendo que ele encapsula o poder e a autoridade de um modo de existência que, muitas vezes, se sobrepõe a outros e gera conflito. Cumpre enfatizar que os espaços de inovação geram interações sociais, políticas e administrativas entre atores, e elas são de natureza ambígua. A materialidade envolvida na inovação tem a capacidade de reformular as relações de poder e a autoridade que constituem produtos territoriais e os cursos de ação que norteiam os grupos que competem pelo controle de espaços, do conhecimento e da autoridade relacionados aos produtos territoriais.

As objeções à planta de processamento coletivo geraram grandes diferenças, a ponto de alguns produtores terem se retirado do projeto. A ideia da planta de processamento coletivo de Merkén nos confronta metodologicamente com o reconhecimento de que uma perspectiva de inovação sócio material cria a oportunidade de explorar as dimensões da 'materialidade do poder', e como manter e fortalecer os campos da semi autonomia. Neste sentido, o que pode ser considerado com um êxito é a recuperação biocultural do Merkén de Santa Juana, por outro lado, o sucesso relativo da planta coletiva de processamento nos apresenta justamente a identificação do espaço ambíguo da inovação. Qual seja, o aspecto mais importante do Merkén como produto patrimonial relacionado ao território está na singularidade das receitas desenvolvidas pelas diversas famílias de merkeneros, todavia, a ampliação e o alcance de novos mercados estão assentados na estandardização do condimento. Em outras palavras, um plano de negócios que vise melhorar as estratégias de mercado passa pela homogeneização do produto e, portanto, pelo eventual desaparecimento das receitas locais.

\section{Conclusões}

Desde uma perspectiva do ator social e do novo materialismo, neste artigo, propusemos que a inovação contemporânea faz emergir um espaço ambíguo para a transformação territorial, e que este deve ser reconceitualizado como uma propriedade da mescla (assemblage) sócio material de práticas bio-culturais e de discursos sociotécnicos e econômicos. Tal espaço guarda traços de similitude entre os atores e as instancias institucionais, e também entre a ideologia de mercado e o conhecimento local, revelados na parcialidade das conexões entre as propostas dos especialistas do desenvolvimento, os agentes dos mercados e os atores territoriais.

A inovação neoliberal produziu mudanças significativas, que levam a começar a pensar uma nova ontologia para o desenvolvimento territorial. Parte deste processo é impulsionado pela importância que adquiriu a revalorização e a identificação dos produtos-alimentos territoriais com potencialidade de mercado. A orientação de organizações globais, como a UNESCO, e os especialistas culturais (antropólogos), ao mobilizar as propriedades intangíveis do patrimônio alimentar territorial na América Latina, baseando-se na 'materialidade da cultura' (i.e, a comida) 
começam a substituir o discurso dos regimes sociotécnicos nos processos de desenvolvimento.

O conhecimento, na perspectiva da inovação sociotécnica se enfocou, principalmente, em como promover descontinuidades técnicas, de modo a acelerar processos de modernização, homogeneização e, com isso, impulsionou mudanças desterritorializadas. A inovação baseada na revalorização das propriedades intangíveis do patrimônio alimentar gerou, por outro lado, um discurso no qual se enfatiza a continuidade do conhecimento local, com a intenção de manter as propriedades patrimoniais de um produto territorial, o que, muitas vezes, invisibiliza mudanças introduzidas pelos próprios produtores.

Em outras palavras, discutir a continuidade e descontinuidade das diferentes formas de conhecimento, que participam em processos de transformação territorial, é um ponto de partida importante. Sugerimos que isto serve para começar a pensar uma nova ontologia da inovação em um mundo contemporâneo globalizado, altamente móvel e onde a interação do global e do local dissolveu fronteiras entre externo e interno, endógeno e exógeno, ou entre causa e consequência. A reflexão, aqui proposta, parte do estudo empírico da produção bio-cultural das pimentas e do Merkén em Santa Juana.

Encontramos que o processo de gentrificação do Merkén estimula as empresas de alimentos a apropriarem-se do patrimônio territorial deste condimento. Assim, são as oportunidades comerciais que geram seu alto valor no mercado, o que acaba por estimular a inovação na manufatura de um Merkén industrial, substituindo o produto artesanal nos mercados de condimentos nacionais e internacionais. A manufatura empresarial luta por controlar propriedades intangíveis do Merkén Mapuche, e nos mostra a importância da 'materialidade do poder' no crescimento da ambiguidade dos espaços de inovação comercial.

Finalmente, destacamos a importância em dar ênfase ao resgate das propriedades bio-culturais dos produtos patrimoniais, alertando para os efeitos da produção destes 'objetos' para um mercado de supervalorização gastronômica. Uma das características distintivas do Merkén artesanal são as receitas familiares, em outras palavras, a diferenciação do produto entre os produtores mesmos constitui as propriedades que o identifica com o território. Esta diversidade de receitas é posta em questão quando se trata de homogeneizar as características específicas da produção e do processamento das pimentas. Apesar do mercado exigir protocolos estandardizados, estes são rechaçados por muitos dos produtores, que os entendem como intervenções que depreciam as 'receitas familiares'.

Nós sustentamos que as práticas dos atores, a exemplo da manutenção da diversidade de procedimentos de obtenção do Merkén, conduzem distintos cursos de ação nos territórios, modificando diretrizes de mudança social e de participação no mercado. Isto nos indica que apenas em parte as inovações sócio materiais de um território são conduzidas pelas 'propriedades' do mercado.

$O$ interesse manifesto dos consumidores em conhecer as origens produtivas dos alimentos que consomem, assim como em experimentar ingredientes de valor patrimonial e com singularidade regional ou étnica, transforma os alimentos em entidades com aspectos simultaneamente culturais e nutritivos. Assim, o afastamento da indústria faz com que a materialidade alimentar adquira agência mobilizadora que favorece a interação entre produto, produtores e consumidores. Esta tendência oferece potencialidades, mas também abre janelas para a disputa 
entre a produção artesanal dos produtos-alimentos patrimoniais e as indústrias de alimentos. O caso do Merkén acaba por enfatizar os elementos intangíveis e culturais como parte dos processos contemporâneos de inovação. O conhecimento local é valorizado e deve ser protegido como valor cultural e de mercado, no entanto, a ambiguidade da inovação neoliberal tem o potencial de gerar conflitos e rupturas.

\section{REFERÊNCIAS}

ACAMPORA, T.; FONTE, M. Productos Típicos, Estrategias de Desarrollo Rural y Conocimiento Local. Revista Ópera, n.7, p. 191-212, 2007.

AGUILERA, I. De la cocina al Estado nación: El ingrediente mapuche. Barcelona: Icaria, 2016. (Observatorio de la Alimentación, 5)

ARCE, A. Negotiating Agricultural Development Entanglements of Bureaucrats in Rural Producers in Western Mexico. Wageningen: PUDOC, 1993. (Wageningen Studies in Sociology).

ARCE, A.; CORTÉS, M. El Merkén : El condimiento que pica el Chile. In: CORTÉS, M.; PERTUZÉC, R. (orgs.) Vida e Historia del Merkén de Santa Juana, Valle de Catiri. Santiago: Universidad de Chile, 2019. P. 2-15 (Serie Ciencias Agronómicas)

ARCE, A.; LONG, N. (eds.) Anthropology, development, and modernities: exploring discourses, counter-tendencies and violence. London: Routledge, 2000.

ARCE, A.; LONG, N. Re-positioning knowledge in the Study of Rural Development. In: SYMES, D.; JANSEN, A. J. Agricultural Restructuring and Rural Change in Europe. Wageningen: Agricultural University of Wageningen, 1994, p. 75-86.

ARCE, A.; MARSDEN, T. The Social Construction of International Food: A new research agenda. Economic Geography, v. 69, n. 3, p.293-311, 1993.

ÁVILA, R.; ALVAREZ, M.; MEDINA, X. (coord.) Alimentos, cocinas e intercambios culinarios: confrontaciones culturales, identidades e resignificaciones. Guadalajara: Universidad de Guadalajara, 2015.

BESTOR, T. How Sushi Went Global. Foreign Policy, n.121, p. 54-63, 2000.

BLANCO, G.; GASTEL, J. van; LAGARRIGUE, A. Assembling responsible food markets: the case of Cooperativa La Manzana in southern Chile. In: SHERWOOD, S.; ARCE, A.; PAREDES, M. (eds.). Food, Agriculture and Social Change: The Everyday Vitality of Latin America. London: Routledge/Earthscan, 2017, p.184-197.

BONANNO, A; SEKINE, K; FEUER, H.N. (eds.). Geographical Indication and Global AgriFood: Development and Democratization. London: Routledge/Earthscan, 2019.

CARVALLO, D.A. Estrategia comunicacional para la empresa Chili from Chile. Lincenciado, Universidad del Desarrollo, Facultad de Diseño, Chile, 2016. Disponível em: https://issuu.com/danilocarvallo/docs/memoria_de_titulo Acesso: 04 fevereiro, 2019.

CHARÃO-MARQUES, F., SCHMITT, C. J.; OLIVEIRA, D. Unfolding agencies and associations of agroecology networks. In: SHERWOOD, S.; ARCE, A.; PAREDES, M. (eds.). Food, Agriculture 
and Social Change: The Everyday Vitality of Latin America. London: Routledge/Earthscan, 2017, p.126-140.

COOLE, D.; FROST, S. New Materialism: Ontology, Agency, and Politics. Durham: Duke University Press, 2010.

CORTÉS, M.; Boza, S. Patrimonio Agroalimentario en Sur de Chile. Elementos para el desarrollo territorial. Santiago: Universidad de Chile, 2017. (Serie Ciencias Agronómicas)

DIARIO ESTRATEGIA. Apertura comercial y el boom de la comida étnica potencian la industria de condimentos. Diario Estrategia. Santiago, 20 dezembro, 2004.

FIA. Estúdio de mercado nacional e internacional de ají. Santiago: Fondo de Innovación Agraria, 2010. Disponível em:

http://bibliotecadigital.fia.cl/bitstream/handle/20.500.11944/1860/ESTUDIO_DE_MERCADO_ NACIONAL_E_INTERNACIONAL_DE_AJI.pdf Acesso: 23 de fevereiro, 2019

FREIDBERG, S. French beans for the masses: a modern historical geography of food in Burkina Faso. Journal of Historical Geography, v.29, n. 3, p. 445-463, 2003.

GEELS, F. W. From sectoral systems of innovation to socio-technical systems. Insights about dynamics and change from sociology and institutional theory. Research Policy, n. 33, p. 897920, 2004.

GOLDFRANK, W. Fresh demand: the consumption of Chilean produce in the United States. In: GEREFFI, G.; KOREZENIEWICZ, M. (eds.) Commodity Chains and Capitalism. Connecticut: Greenwood Press, 1994.

HOBART, M. (ed.) An Anthropological Critique of Development: The Growth of Ignorance. London: Routledge, 1993.

INTA. Alimentos y cocinas regionales de América: Resumen del primer foro, Buenos Aires, 2017. Buenos Aires: Ediciones INTA, 2018. Disponível em:

http://www.forodealimentosycocinasregionales.com Acesso: 23 outubro, 2019.

KEMP, R.; SCHOT, J.; HOOGMA, R. Regime shifts to sustainability through processes of niche formation: the approach of Strategic Niche Management. Technology Analysis \& Strategic Management, v. 10, n. 2, p. 175-196, 1998.

LONG, N.; LONG, A. (eds.) Battlefields of Knowledge: The Interlocking of Theory and Practice in Social Research and Development. London: Routledge, 1992.

MONTECINOS, S. (ed.) Cocinas, Alimentos y Símbolos: Estado del arte del patrimonio culinario en Chile. Santiago: Consejo Nacional de la Cultura y las Artes, 2017.

MOORE, S. F. Law and Social Change. The Semi-Autonomous Social Field as an Appropriate Subject of Study. Law and Society Review, n. 7, p. 719-746, 1973.

OLIVIER de SARDAN J.-P. Anthropologie et développement: essai en socio-anthropologie du changement social. Paris: Karthala, 1995.

OYARZÚN, M.T; RIVEROS, H.; VANDECANDELAERE, E. Cómo promover la calidad vinculada al origen para contribuir al desarrollo en América Latina: enseñanzas de cuatro casos 
piloto. Santiago: FAO, 2013. Disponível em: http://repiica.iica.int/docs/B3269e/B3269e.pdf Acesso: 02 fev. 2019.

PINTO, H. S.; SIMÕES, R.A. Cultura Alimentar como Patrimônio Imaterial da Humanidade: desafios e oportunidades para a gastronomia brasileira. Brasília: Núcleo de Estudos e Pesquisas/CONLEG/Senado, 2016. (Texto para Discussão no 195). Disponivel em: www.senado.leg.br/estudos Acesso: 26 outubro, 2019

POTTIER, J. Practising Development: Social Science Perspectives. London: Routledge, 1993.

RAJALAHTI, R., WILLEM J., PEHU, E. Agricultural Innovation Systems: From Diagnostics toward Operational Practices. Agriculture and Rural Development Discussion. The International Bank for Reconstruction and Development/ The World Bank, 2008. 87 pp. (Paper, 38)

ROSEBERRY, W. The Rise of Yuppie Coffees and the Reimagination of Class in the United States. American Anthropologist, v. 98, n. 4, p. 762-775, 1996.

STRATHERN, M. Partial Connections. Maryland: Rowman \& Littlefield Publishers, 1991.

WORLD BANK. Enhancing Agricultural Innovation: How to Go Beyond the Strengthening of Research Systems. Washington, DC: World Bank, 2006.

Alberto Arce. PhD Sociologia. Professor Emérito da Universidade de Wageningen, Holanda, e professor visitante na Universidade Federal do Rio Grande do Sul, Brasil. alberto.arce@wur.nl

Flávia Charão Marques. Dra Desenvolvimento Rural. Universidade Federal do Rio Grande do Sul. Av. João Pessoa, 31. Porto Alegre/RS, CEP 90040-000. flavia.marques@ufrgs.br

Como citar: ARCE, Alberto; CHARÃO-MARQUES, Flávia. Espaços ambíguos e a inovação neoliberal contemporânea: o caso do Merkén. Redes (St. Cruz Sul, Online), Santa Cruz do Sul, v. 25, n. 1, jan. 2020. ISSN 1982-6745. DOI: https://doi.org/10.17058/redes.v25I1.14389.

\section{CONTRIBUIÇÃO DE CADA AUTOR}

Fundamentação teórico-conceitual e problematização: Alberto Arce, Flávia Charão-Marques Pesquisa de dados e análise estatística: Alberto Arce, Flávia Charão-Marques Elaboração de figuras e tabelas: Alberto Arce, Flávia Charão-Marques Fotos: não se aplica; Elaboração e redação do texto: Alberto Arce, Flávia Charão-Marques Seleção das referências bibliográficas: Alberto Arce, Flávia Charão-Marques 